\title{
THE EFFECT OF RISK ON INVESTMENT: NEW EVIDENCE
}

\section{Tingting Que}

Corresponding Author: Tingting Que, College of Business, University of Alabama in Huntsville $9 \mathbf{m}+256-824-6703$
$\square \underline{\text { tingting.que@uah.edu }}$

\begin{abstract}
Previous results on the relation between risk and investment are mixed, partly due to endogeneity. To alleviate the effects of this bias, we adopt a generalized method of moments (GMM) dynamic panel estimator to investigate the relation. We find that the puzzling positive sensitivity of investment (i.e. firm's investment rate) to systematic risk as frequently documented in previous studies disappears. Further, we show that the more irreversible the firm's investments are, the more valuable is the option to delay investment when risk is high, which supports the model with irreversible investment.
\end{abstract}

Keywords: risk, investment, endogeneity, GMM, capital irreversibility

\section{Introduction}

The relation between risk and investment has been an important research topic for several decades. Despite an extensive theoretical literature predicting a negative impact of risk on investment (e.g., Bernanke (1983); Smith and Stulz (1985); McDonald and Siegel (1986); Froot et al. (1993); Dixit and Pindyck (1994); Abel and Eberly (1996)), empirical results are mixed. While some studies support the theoretical prediction (e.g., Leahy and Whited (1996); Gulen and Ion (2016); Julio and Yook (2012)), Bulan (2005) and Panousi and Papanikolaou (2012) show that idiosyncratic and systematic risk affect investment in different ways. In particular, they find that systematic risk actually encourages investment while idiosyncratic risk does the opposite. One goal of this paper is to reconcile these mixed empirical results.

We start by examining the average relation between risk and investment (i.e. firm's investment rate) using the conventional ordinary least squares (OLS) model with fixed effects. We confirm that an increase in idiosyncratic volatility depresses investment, while an increase in systematic volatility encourages investment.

Since systematic volatility depends on the firm's systematic risk exposure (beta) as well as market and industry risk, we further decompose systematic volatility into its individual components to examine the role of covariance and other components. Surprisingly, we find that a firm's exposure to systematic risk is positively correlated with investment. The result stands in contrast with the view that greater systematic risk tends to make investment less desirable.

We acknowledge that the OLS model may give rise to three potential sources of endogeneity. First, the OLS model ignores unobserved heterogeneity by assuming that neither the risk variables nor the control variables are correlated to unobserved firm characteristics. Second, OLS estimation relies on the assumption that none of the risk variables or the control variables is correlated with the error term. But if investment and risk are simultaneously determined, then this assumption is clearly violated, which leads to biased OLS estimates.

Lastly, although the fixed-effects estimation eliminates unobserved heterogeneity, it potentially introduces dynamic endogeneity. The fixed-effects estimation relies on a strict exogeneity assumption which requires that in our context, the risk variables we observe today are completely 
independent of any past, present and future investment. This assumption is likely to be violated if contemporaneous risk variables depend on past realization of investment, and thus fixed-effects estimation is likely to be inconsistent.

While there is substantial economic justification to suspect that the risk variables are not strictly exogenous, we confirm this with an econometric test of strict exogeneity suggested by Wooldridge (2010). The results show the risk variables are not strictly exogenous. Thus, dynamic endogeneity is likely to be a major source of bias in the baseline model.

Consistent estimation of the relation between risk and investment requires the use of an estimation technique which controls for unobserved heterogeneity and simultaneity while exploiting the dynamic association between risk and investment. A promising estimation technique is the GMM dynamic panel estimator. This estimator, first proposed by Holtz-Eakin et al. (1988) and Arellano and Bond (1991) and further developed by Arellano and Bover (1995) and Blundell and Bond (1998), provides an excellent econometric specification to deal with the abovementioned issues.

When the estimation is carried out using the GMM dynamic panel estimator, the puzzling positive sensitivity of investment to systematic risk disappears. We further apply the GMM estimator to estimate the relation between investment and various components of systematic risk and document a clear negative response of investment to systematic risk components. These results support the prediction that the greater the systematic risk the less the incentive to invest.

Both the traditional view (e.g. the capital asset pricing model (CAPM)) and the real option theory predict that greater uncertainty tends to make investment less desirable. However, the traditional view asserts that it is only the systematic risk that should matter for firm investment, while real option theory predicts that it is the total risk that should matter for investment. To this point, our GMM estimations show that both systematic and idiosyncratic risk have negative impacts on firm investment. Therefore, we take the next step to examine the predictions of real option theory in the context of capital irreversibility.

The ability to delay investment is valuable when the investment is irreversible, and the future is uncertain. The irreversibility of investment stems from capital specificity at the industry and/or at the firm level. We implement sample splits according to the firm's degree of irreversibility and reestimate the relation between investment and risk using a GMM dynamic panel estimator in the two subsamples. We provide empirical support for the prediction of real options models that the more irreversible the firm's investments are, the more valuable is the option to delay investment when risk is high.

The main contribution of this paper is to reconcile mixed evidence on the relation between risk and investment. Prior studies documenting a puzzling positive sensitivity of investment to systematic volatility may have inadvertently relied on inconsistent estimation procedures. By implementing a GMM dynamic panel estimator that eliminates the major sources of endogeneity, we show that the positive sign is replaced by a negative relation between investment and systematic risk.

This paper also contributes to the literature that uses the GMM dynamic panel estimation in economics and finance where unobserved heterogeneity and dynamic endogeneity are prevalent and truly exogenous instruments are difficult to find. Examples of these studies include Caselli et al. (1996), Blundell and Bond (1998), Beck et al. (2000), Erickson and Whited (2000) and Wintoki et al. (2012). In estimating the relation between investment and risk, we apply the GMM dynamic panel estimator to control for unobserved heterogeneity, simultaneity and dynamic endogeneity.

In addition, this paper provides empirical support for the prediction of real options models. Our results show that the greater the degree of asset-specificity of capital (and hence the more 
irreversible the firm's investments are), the more valuable is the option to delay investment when uncertainty is high.

The remainder of the paper is organized as follows. Section 2 describes the sample. Section 3 provides empirical results. Section 4 concludes.

\section{Sample}

Following previous empirical work in the risk and investment literature, the sample includes all publicly traded firms in Compustat over the period 1970 to 2005, excluding firms in the financial (SIC code 6000-6999), utilities (SIC code 4900-4949), and government-regulated industries (SIC code > 9000). Firm-year observations with missing SIC codes, with missing values for investment, Tobin's $Q$, cash flows, size, leverage, stock returns, and with negative book values of capital are dropped. Firms with fewer than 40 weekly observations in that year are also excluded. The initial sample includes a total of 101,378 firm-year observations. Finally, data are winsorized by year at the $0.5 \%$ and $99.5 \%$ levels in all specifications. Descriptive statistics and correlations are presented in Table 1.

\section{Table 1: Summary statistics}

Investment rate $\left(\operatorname{Capx}_{t} / A_{t-1}\right)$ is defined as the ratio of capital expenditure to book assets. Our measure of idiosyncratic risk, $\log \left(\sigma_{i, t-1}^{\text {idio }}\right)$, is constructed from a regression of weekly firm-level returns on the CRSP VW index and the corresponding industry portfolio. Systematic volatility $\left(\log \left(\sigma_{t-1}^{\text {syst }}\right)\right)$ is defined as the (log of the) square root of the difference between the firm's total variance and its idiosyncratic variance. Market volatility $\left(\log \left(\sigma_{t-1}^{m k t}\right)\right)$ is defined as the (log of the) square root of the variance of CRSP VW index. $\beta_{i, t-1}^{m k t}$ and $\beta_{i, t-1}^{i n d}$ are coefficient estimates from the regression of weekly firm-level returns on the CRSP VW index and the corresponding industry portfolio. Industry volatility $\left(\log \left(\sigma_{t-1}^{\text {ind }}\right)\right)$ defined as the (log of the) square root of the variance of VW industry portfolio. The sample period is 1970 to 2005.

\begin{tabular}{|c|c|c|c|c|c|c|c|}
\hline \multicolumn{8}{|c|}{ Panel A: Descriptive Statistics ( $N=101,378)$} \\
\hline Variables & \multicolumn{6}{|c|}{ Mean } & Std Dev \\
\hline $\operatorname{Capx}_{t} / A_{t-1}$ & \multicolumn{6}{|c|}{0.071} & 0.078 \\
\hline $\log \left(\sigma_{i, t-1}^{i d i o}\right)$ & \multicolumn{6}{|c|}{-0.959} & 0.545 \\
\hline $\log \left(\sigma_{t-1}^{\text {syst }}\right)$ & \multicolumn{6}{|c|}{-1.949} & 0.735 \\
\hline $\log \left(\sigma_{t-1}^{m k t}\right)$ & \multicolumn{6}{|c|}{-2.045} & 0.332 \\
\hline$\beta_{i, t-1}^{m k t}$ & \multicolumn{6}{|c|}{0.591} & 1.307 \\
\hline $\log \left(\sigma_{t-1}^{i n d}\right)$ & \multicolumn{6}{|c|}{-1.742} & 0.354 \\
\hline$\beta_{i, t-1}^{i n d}$ & \multicolumn{6}{|c|}{0.374} & 0.998 \\
\hline \multicolumn{8}{|c|}{ Panel B: Sample Correlations ( $N=101,378)$} \\
\hline Variables & $\operatorname{Capx}_{t} / A_{t-1}$ & $\log \left(\sigma_{i, t-1}^{\text {idio }}\right)$ & $\log \left(\sigma_{t-1}^{s y s t}\right)$ & $\log \left(\sigma_{t-1}^{m k t}\right)$ & $\beta_{i, t-1}^{m k t}$ & $\log \left(\sigma_{t-1}^{i n d}\right)$ & $\beta_{i, t-1}^{i n d}$ \\
\hline $\operatorname{Capx}_{t} / A_{t-1}$ & 1 & & & & & & \\
\hline $\log \left(\sigma_{i, t-1}^{i d i o}\right)$ & -0.096 & 1 & & & & & \\
\hline $\log \left(\sigma_{t-1}^{s y s t}\right)$ & 0.019 & 0.384 & 1 & & & & \\
\hline $\log \left(\sigma_{t-1}^{m k t}\right)$ & -0.038 & 0.186 & 0.342 & 1 & & & \\
\hline$\beta_{i, t-1}^{m k t}$ & 0.002 & 0.114 & 0.217 & 0.005 & 1 & & \\
\hline $\log \left(\sigma_{t-1}^{i n d}\right)$ & -0.055 & 0.274 & 0.389 & 0.776 & 0.008 & 1 & \\
\hline$\beta_{i, t-1}^{i n d}$ & 0.036 & -0.051 & 0.214 & -0.012 & -0.767 & 0.016 & 1 \\
\hline
\end{tabular}




\section{Empirical Results}

\subsection{Baseline Model}

In this section, we use the OLS model with fixed-effects as the baseline model to examine the response of investment to idiosyncratic and systematic volatility.

The baseline measure of idiosyncratic volatility is constructed using weekly data on stock returns from CRSP (Bulan (2005), Panousi and Papanikolaou (2012)). For every firm $i$ and every year $t$, we regress the firm's return on the value-weighted market portfolio, $R_{M K T}$, and on the corresponding value-weighted industry portfolio, $R_{I N D}$, based on the (Fama \& French 1997) 30-industry classification, across the 52 weekly observations.

$$
R_{i, \tau}=\alpha_{1, i}+\beta_{i}^{m k t} R_{M K T, \tau}+\beta_{i}^{\text {ind }} R_{I N D, \tau}+\varepsilon_{i, \tau}
$$

where $\tau$ indexes weeks. Then idiosyncratic risk is the log volatility of the regression residuals

$$
\log \left(\sigma_{i, t-1}^{\text {idio }}\right)=\log \sqrt{\sum_{\tau \in t} \varepsilon_{i, \tau}^{2}} .
$$

Systematic volatility is then defined as the (log of the) square root of the difference between the firm's total variance and its idiosyncratic variance.

The response of investment to idiosyncratic and systematic risk is estimated using the following equation:

$$
\operatorname{Capx}_{t} / A_{t-1}=\gamma_{0}+\beta_{1} \log \left(\sigma_{i, t-1}^{\text {idio }}\right)+\beta_{2} \log \left(\sigma_{t-1}^{\text {syst }}\right)+\gamma_{1} Z_{i, t-1}+\delta_{i}+\theta_{t}+\omega_{i, t},
$$

where the dependent variable is the firm's investment rate $\left(\operatorname{Capx}_{t} / A_{t-1}\right)$ and $Z_{i, t-1}$ is a vector of control variables: (i) log Tobin's $Q$; (ii) the ratio of cash flows to assets $\left(C F_{t-1} / A_{t-2}\right)$; (iii) log firm size; (iv) the firm's own stock return $\left(R_{t-1}\right)$; and $(\mathrm{v})$ log firm leverage, measured as the ratio of equity to assets $\left(\log \left(E_{t-1} / A_{t-1}\right)\right)$. Depending on the specification, we include firm $\left(\delta_{i}\right)$ or year dummies $\left(\theta_{t}\right)$. Finally, the errors $\left(\omega_{i, t}\right)$ are clustered at the firm level.

The estimates of Equation (3) are reported in the first column of Table 2. The coefficient on idiosyncratic volatility is of $-1 \%$ and statistically significant. The sign of the coefficient is consistent with Panousi and Papanikolaou (2012), but the magnitude is smaller due to the reason that we use book assets instead of replacement value of capital (see, Salinger and Summers (1983)) in the dependent variable in Equation (3). However, the coefficient on systematic volatility is positive and significant $(0.2 \%)$. The positive sensitivity of investment to systematic volatility is puzzling. All else equal, an increase in systematic volatility increases the firms' cost of capital and therefore should decrease investment.

Since the measure of systematic volatility depends on the firm's systematic risk exposure (beta) as well as the amount of market and industry risk, we decide to decompose systematic volatility into individual components in an attempt to explain the positive response of investment to systematic volatility. 


\section{Table 2: Baseline OLS model of investment on risk}

The table reports OLS estimation results of Equations (3) and (4), where the dependent variable is the investment rate $\left(\right.$ Capx $\left._{t} / A_{t-1}\right)$. The idiosyncratic risk, $\log \left(\sigma_{i, t-1}^{i d i o}\right)$, is constructed from a regression of weekly firm-level returns on the CRSP $\mathrm{VW}$ index and the corresponding industry portfolio. Systematic volatility $\left(\log \left(\sigma_{t-1}^{\text {syst }}\right)\right)$ defined as the $(\log$ of the $)$ square root of the difference between the firm's total variance and its idiosyncratic variance. Market volatility $\left(\log \left(\sigma_{t-1}^{m k t}\right)\right)$ is defined as the (log of the) square root of the variance of CRSP VW index. $\beta_{i, t-1}^{m k t}$ and $\beta_{i, t-1}^{\text {ind }}$ are coefficient estimates from the regression of weekly firm-level returns on the CRSP VW index and the corresponding industry portfolio. Industry volatility $\left(\log \left(\sigma_{t-1}^{\text {ind }}\right)\right)$ defined as the (log of the) square root of the variance of VW industry portfolio. Financial control variables include lagged values of: Tobin's $Q \log \left(Q_{t-1}\right)$ defined as in Fazzari et al. (1988); operating cash flows $\left(C F_{t-1} / A_{t-2}\right)$ defined as the ratio of operating income to book assets; the firm's size $\left(\log \left(A_{t-1}\right)\right)$ defined as the log value of book assets; the firm's stock return $\left(R_{t-1}\right)$; leverage $\left(E_{t-1} / A_{t-1}\right)$ defined as the ratio of book equity to book assets. The coefficients of these control variables are suppressed for brevity. The sample period is 1970 to 2005 . F, T denotes firm and time fixed effects, and $p$-values are reported in parentheses. ${ }^{* * *}$, **, and * indicate significance at the $1 \%, 5 \%$ and $10 \%$ levels, respectively.

\begin{tabular}{|c|c|c|c|}
\hline $\operatorname{Capx}_{t} / A_{t-1}$ & 1 & 2 & 3 \\
\hline \multirow[t]{2}{*}{$\log \left(\sigma_{i, t-1}^{i d i o}\right)$} & $-0.010^{* * *}$ & $-0.002^{* * *}$ & $-0.009 * * *$ \\
\hline & (0.000) & (0.005) & $(0.000)$ \\
\hline \multirow[t]{2}{*}{$\log \left(\sigma_{t-1}^{s y s t}\right)$} & $0.002^{* * *}$ & & \\
\hline & $(0.000)$ & & \\
\hline \multirow[t]{2}{*}{$\log \left(\sigma_{t-1}^{m k t}\right)$} & & -0.001 & $-0.034^{* * *}$ \\
\hline & & (0.589) & $(0.000)$ \\
\hline \multirow[t]{2}{*}{$\beta_{i, t-1}^{m k t}$} & & $0.003^{* * *}$ & $0.001^{* * *}$ \\
\hline & & $(0.000)$ & $(0.000)$ \\
\hline \multirow[t]{2}{*}{$\log \left(\sigma_{t-1}^{i n d}\right)$} & & $-0.011^{* * *}$ & 0.001 \\
\hline & & $(0.000)$ & (0.704) \\
\hline \multirow[t]{2}{*}{$\beta_{i, t-1}^{i n d}$} & & $0.002^{* * *}$ & $0.001^{* * *}$ \\
\hline & & (0.000) & $(0.004)$ \\
\hline Financial controls & Yes & No & Yes \\
\hline Observations & 101,378 & 101,378 & 101,378 \\
\hline$R^{2}$ & 0.555 & 0.494 & 0.555 \\
\hline Fixed effects & $F, T$ & $\mathrm{~F}$ & $F, T$ \\
\hline
\end{tabular}

We estimate the response of investment to each component of systematic volatility and idiosyncratic risk using the following reduced-form equation:

$$
\text { Capx }_{t} / A_{t-1}=\gamma_{0}+\gamma_{1} \log \left(\sigma_{i, t-1}^{i d i o}\right)+\gamma_{2} \log \left(\sigma_{t-1}^{m k t}\right)+\gamma_{3} \beta_{i, t-1}^{m k t}+\gamma_{4} \log \left(\sigma_{t-1}^{\text {ind }}\right)+\gamma_{5} \beta_{i, t-1}^{\text {ind }}+\gamma_{6} Z_{i, t-1}+\delta_{i}+\theta_{t}+\omega_{i, t}
$$

where four additional regressors are included: market volatility $\left(\log \left(\sigma_{t-1}^{m k t}\right)\right)$ defined as the (log of the) square root of the variance of CRSP VW index; $\beta_{i, t-1}^{m k t}$ and $\beta_{i, t-1}^{i n d}$ are coefficient estimates from the regression of weekly firm-level returns on the CRSP VW index and the corresponding industry portfolio in Equation (1); industry volatility $\left(\log \left(\sigma_{t-1}^{\text {ind }}\right)\right)$ defined as the (log of the) square root of the variance of VW industry portfolio.

The second and third column in Table 2 present estimates of Equation (4). In the second column, the coefficient on idiosyncratic volatility is negative and significant $(-0.2 \%)$; the coefficients on systematic risk exposure $\left(\beta_{i, t-1}^{m k t}\right.$ and $\left.\beta_{i, t-1}^{\text {ind }}\right)$ are positive and significant whereas the coefficients on 
market and industry risk are negative (only the coefficient on industry risk is significant). The last column presents the results of the benchmark estimation for Equation (4). The coefficient on idiosyncratic volatility stays negative and significant. The coefficient on market risk is negative and significant whereas the coefficient on industry risk is positive but insignificant. Invariably, the coefficients on systematic risk exposure $\left(\beta_{i, t-1}^{m k t}\right.$ and $\left.\beta_{i, t-1}^{\text {ind }}\right)$ are positive and significant.

Our estimates are consistent with Bloom (2009), who finds a negative relation between investment and the volatility of the market portfolio. Nevertheless, the positive response of investment to a firm's exposure to systematic risk remains puzzling.

\subsection{Testing for Strict Exogeneity}

To investigate the puzzling positive sensitivity of investment to systematic risk, we need to realize that three potential sources of endogeneity may arise from estimating Equation (3) and (4) using the baseline model. Firstly, the OLS model ignores unobserved heterogeneity by assuming that neither the risk variables nor the control variables are correlated with unobserved firm characteristics. But it is quite easy to see that this assumption is likely to be violated when estimating the relation between investment and risk. For example, a firm' growth opportunity not only has a direct impact on investment but is also likely to be correlated with the firm's exposure to systematic risk. This suggests that OLS estimates are likely to be severely biased.

Aside from unobserved heterogeneity, OLS estimation relies on the assumption that neither the risk variables nor the control variables are correlated with the error term, $\omega_{i, t}$. If investment and risk are simultaneously determined, then this assumption is clearly violated, and OLS yields biased estimates.

Lastly, although the fixed-effects estimation employed in the previous section eliminates the unobserved heterogeneity, it potentially introduces dynamic endogeneity. The fixed-effects estimation relies on a strict exogeneity assumption which implies that, in our context the risk variables that we observe today is completely independent of any past, present and future investment. This assumption is likely to be violated if there is a dynamic relation between firms' investment and risk, and thus fixed-effects estimation is likely to be inconsistent.

While there is substantial economic justification to suspect that the risk variables are not strictly exogenous, we need to confirm this with an econometric test of strict exogeneity.

Wooldridge (2010) present a regression-based test for strict exogeneity that is relatively easy to implement. If $X_{i, t-1}$ contains the explanatory variables, a test of strict exogeneity is obtained by carrying out fixed-effects estimation on the equation:

$$
\operatorname{Capx}_{t} / A_{t-1}=\alpha+\beta X_{i, t-1}+\gamma Y_{i, t+1}+\delta_{i}+\theta_{t}+\omega_{i, t}
$$

Where $Y_{i, t+1}$ is a forward subset of $X_{i, t-1} . X$ includes idiosyncratic and systematic risk, market volatility $\left(\log \left(\sigma_{t-1}^{m k t}\right)\right), \beta_{i, t-1}^{m k t}, \beta_{i, t-1}^{i n d}$ and industry volatility $\left(\log \left(\sigma_{t-1}^{i n d}\right)\right)$. Under the null hypothesis of strict exogeneity, $Y=0$. Intuitively, if $Y \neq 0$, then current risk measures depend on past investment rate (or conversely, present investment affects firm's future risk). Thus, if we can reject the hypothesis, then fixed-effects estimation is likely to be biased by the presence of dynamic endogeneity and we are likely to obtain less biased and more consistent estimates using a dynamic estimation procedure.

Table 3 presents the results of estimating Equation (5), with different subsets of the risk variables, $Y_{i, t+1}$. In every specification in which they are included, the coefficient estimates for the forward 
values of idiosyncratic and systematic risk, $\beta_{i, t-1}^{m k t}$ and $\beta_{i, t-1}^{i n d}$ are significantly different from zero. This suggests that none of these risk variables are strictly exogenous and all of these variables adjust to firm investment.

\section{Table 3: Tests of strict exogeneity}

The table reports fixed-effects estimation results of Equation (5), where the dependent variable is the investment rate $\left(\right.$ Capx $\left._{t} / A_{t-1}\right)$. Explanatory variables include idiosyncratic risk $\left(\log \left(\sigma_{i, t-1}^{\text {idio }}\right)\right)$, systematic risk $\left(\log \left(\sigma_{t-1}^{\text {syst }}\right)\right)$, market volatility $\left(\log \left(\sigma_{t-1}^{\text {mkt }}\right)\right)$, $\beta_{i, t-1}^{\text {mkt }}, \beta_{i, t-1}^{\text {ind }}$, industry volatility $\left(\log \left(\sigma_{t-1}^{\text {ind }}\right)\right)$ and forward values of these risk variables. Financial control variables include lagged values of: Tobin's $Q \log \left(Q_{t-1}\right)$, operating cash flows $\left(C F_{t-1} / A_{t-2}\right)$, the firm's size $\left(\log \left(A_{t-1}\right)\right)$, the firm's stock return $\left(R_{t-1}\right)$ and leverage $\left(E_{t-1} / A_{t-1}\right)$. The definitions of these variables are the same as in Table 2 . The coefficients of these control variables are suppressed for brevity. The sample period is 1970 to 2005. F, $T$ denotes firm and time fixed effects, and $p$-values are reported in parentheses. ${ }^{* * *}, * *$, and $*$ indicate significance at the $1 \%, 5 \%$ and $10 \%$ levels, respectively.

\begin{tabular}{|c|c|c|c|}
\hline $\operatorname{Capx}_{t} / A_{t-1}$ & 1 & 2 & 3 \\
\hline \multirow[t]{2}{*}{$\log \left(\sigma_{i, t-1}^{i d i o}\right)$} & $-0.010^{* * *}$ & $-0.004^{* * *}$ & $-0.009 * * *$ \\
\hline & $(0.000)$ & (0.005) & $(0.000)$ \\
\hline \multirow[t]{2}{*}{$\log \left(\sigma_{t-1}^{s y s t}\right)$} & $0.002^{* * *}$ & & \\
\hline & $(0.000)$ & & \\
\hline \multirow[t]{2}{*}{$\log \left(\sigma_{t-1}^{m k t}\right)$} & & -0.002 & -0.001 \\
\hline & & $(0.226)$ & (0.903) \\
\hline \multirow[t]{2}{*}{$\beta_{i, t-1}^{m k t}$} & & $0.003^{* * *}$ & $0.001^{* * *}$ \\
\hline & & $(0.000)$ & (0.002) \\
\hline \multirow[t]{2}{*}{$\log \left(\sigma_{t-1}^{i n d}\right)$} & & $-0.015^{* * *}$ & $-0.003^{*}$ \\
\hline & & $(0.000)$ & (0.091) \\
\hline \multirow[t]{2}{*}{$\beta_{i, t-1}^{i n d}$} & & $0.003^{* * *}$ & $0.001^{* * *}$ \\
\hline & & $(0.000)$ & (0.009) \\
\hline \multirow[t]{2}{*}{$\log \left(\sigma_{i, t+1}^{i d i o}\right)$} & $-0.011^{* * *}$ & $-0.013^{* * *}$ & $-0.009 * * *$ \\
\hline & $(0.000)$ & $(0.000)$ & $(0.000)$ \\
\hline \multirow[t]{2}{*}{$\log \left(\sigma_{t+1}^{s y s t}\right)$} & $0.006^{* * *}$ & & \\
\hline & $(0.000)$ & & \\
\hline \multirow[t]{2}{*}{$\beta_{i, t+1}^{m k t}$} & & $0.006^{* * *}$ & $0.004^{* * *}$ \\
\hline & & (0.000) & $(0.000)$ \\
\hline \multirow[t]{2}{*}{$\beta_{i, t+1}^{\text {ind }}$} & & $0.008^{* * *}$ & $0.006^{* * *}$ \\
\hline & & (0.000) & $(0.000)$ \\
\hline Financial controls & Yes & No & Yes \\
\hline Observations & 101,378 & 101,378 & 101,378 \\
\hline$R^{2}$ & 0.560 & 0.490 & 0.560 \\
\hline Fixed effects & $F, T$ & $\mathrm{~F}$ & $F, T$ \\
\hline
\end{tabular}

Overall, the results from Table 3 suggest the risk variables are not strictly exogenous. Thus, dynamic endogeneity is likely to be a major source of bias in estimating the relation between investment and risk. 


\subsection{Estimating the Relation between Investment and Risk using a GMM Dynamic Panel Estimator}

Consistent estimation of Equations (3) and (4) requires the use of an estimation technique which controls for unobserved heterogeneity and simultaneity while exploiting the dynamic association between risk and investment.

An appealing estimation technique is the GMM dynamic panel estimator. This estimator, first proposed by Holtz-Eakin et al. (1988) and Arellano and Bond (1991) and further developed by Arellano and Bover (1995) and Blundell and Bond (1998), provides an excellent econometric framework for dealing with the endogeneity issues. Moreover, as Nickell (1981) shows, when estimating a dynamic panel data, a bias arises in the "small T, large N" context. Our sample has a time dimension $(T=36)$ and a large firm dimension $(N=2,816)$. GMM dynamic panel estimator is designed for small-T large-N panels.

The dynamic GMM estimator replaces the strict exogeneity assumption with a weaker form of exogeneity, sequential exogeneity. The sequential exogeneity assumption allows the risk variables to be determined by past and present realizations of investment, but not future values. This is a fairly reasonable assumption.

This assumption implies that the risk/investment relation should be treated as a dynamic unobserved effects model and Equations (2) and (3) should be estimated as:

$$
\operatorname{Capx}_{t} / A_{t-1}=\alpha\left(\operatorname{Capx}_{t-1} / A_{t-2}\right)+\beta X_{i, t-1}+\gamma Z_{i, t-1}+\delta_{i}+\theta_{t}+\omega_{i, t}
$$

Where $X$ includes idiosyncratic and systematic risk, market volatility $\left(\log \left(\sigma_{t-1}^{m k t}\right)\right), \beta_{i, t-1}^{m k t}, \beta_{i, t-1}^{i n d}$ and industry volatility $\left(\log \left(\sigma_{t-1}^{i n d}\right)\right)$.

Arellano and Bond (1991) develop a first difference GMM estimator by transforming e Equation (6) into a system of $T-1$ equations in first differences:

$$
\Delta \operatorname{Capx} / A_{i}=\Delta \beta X_{i}+\Delta \omega_{i}
$$

Where $X_{i}$ includes the risk variables, control variables and lagged investment rates. This step eliminates the unobserved heterogeneity and allows us to have a model where our risk variables can be arbitrarily correlated with any unobserved firm characteristics.

As Arellano and Bover (1995) and Blundell and Bond (1998) point out, we can improve the GMM estimator by including the equations in levels in the estimation procedure. We can use the firstdifferenced variables as instruments for the equations in levels. This will produce a system GMM estimator. The system GMM estimator enables us to obtain efficient estimates while maintaining all the essential elements of controlling for unobserved heterogeneity, simultaneity and dynamic endogeneity.

The basic steps underlying this estimation strategy is as follows. First, the regression equation of investment on risk is written as a dynamic model that includes lagged investment as an explanatory variable. Next, we can take first-difference and carry out GMM estimation using lagged values of the risk, as well as lagged values of investment as GMM instruments.

Table 4 presents the GMM dynamic panel estimator of investment on risk. We report the results in the same order as in Table 2. The first column reports the GMM estimation of investment on 
idiosyncratic and systematic risk. The coefficient on idiosyncratic volatility remains statistically negative $(-0.5 \%)$. However, the positive sign on systematic volatility has disappeared, instead, the coefficient on systematic volatility is negative $(-0.1 \%)$ and statistically significant. Columns 2 and 3 present the results of investment on various components of systematic volatility. The coefficients on systematic risk exposure $\left(\beta_{i, t-1}^{m k t}\right.$ and $\left.\beta_{i, t-1}^{\text {ind }}\right)$ are all negative: the coefficients on $\beta_{i, t-1}^{\text {ind }}$ are significant in both columns and the coefficients on $\beta_{i, t-1}^{m k t}$ statistically significant in column 3 .

\section{Table 4: GMM dynamic panel estimator of investment on risk}

The table reports the GMM dynamic panel estimator of investment on risk, where the dependent variable is the investment rate $\left(\operatorname{Capx}_{t} / A_{t-1}\right)$. Our measure of idiosyncratic risk, $\log \left(\sigma_{i, t-1}^{i d i o}\right)$, is constructed from a regression of weekly firm-level returns on the CRSP VW index and the corresponding industry portfolio. Systematic volatility $\left(\log \left(\sigma_{t-1}^{\text {syst }}\right)\right)$ is defined as the (log of the) square root of the difference between the firm's total variance and its idiosyncratic variance. Market volatility $\left(\log \left(\sigma_{t-1}^{m k t}\right)\right)$ is defined as the (log of the) square root of the variance of CRSP VW index. $\beta_{i, t-1}^{m k t}$ and $\beta_{i, t-1}^{\text {ind }}$ are coefficient estimates from the regression of weekly firm-level returns on the CRSP VW index and the corresponding industry portfolio. Industry volatility $\left(\log \left(\sigma_{t-1}^{\text {ind }}\right)\right)$ defined as the (log of the) square root of the variance of $\mathrm{VW}$ industry portfolio. Financial control variables include lagged values of the investment rate $\left(\operatorname{Lag}\left(\operatorname{Capx}_{t} / A_{t-1}\right)\right)$, lagged values of: Tobin's $Q \log \left(Q_{t-1}\right)$ defined as in Fazzari et al. (1988): operating cash flows $\left(C F_{t-1} / A_{t-2}\right)$ defined as the ratio of operating income to book assets; the firm's $\operatorname{size}\left(\log \left(A_{t-1}\right)\right)$ defined as the log value of book assets; the firm's stock return $\left(R_{t-1}\right)$; leverage $\left(E_{t-1} / A_{t-1}\right)$ defined as the ratio of book equity to book assets. The coefficients of these control variables are suppressed for brevity. The sample period is 1970 to 2005 . $F$ denotes firm fixed effects, $T$ denotes time fixed effects. The standard errors are clustered at the firm-level, and $p$-values are reported in parentheses. $* * *, * *$, and $*$ indicate significance at the $1 \%, 5 \%$ and $10 \%$ levels, respectively.

\begin{tabular}{|c|c|c|c|}
\hline $\operatorname{Capx}_{t} / A_{t-1}$ & 1 & 2 & 3 \\
\hline \multirow[t]{2}{*}{$\log \left(\sigma_{i, t-1}^{i d i o}\right)$} & $-0.005^{* * *}$ & $-0.003^{* *}$ & $-0.004^{* * *}$ \\
\hline & $(0.000)$ & (0.012) & (0.000) \\
\hline \multirow{2}{*}{$\log \left(\sigma_{t-1}^{s y s t}\right)$} & $-0.001^{* *}$ & & \\
\hline & $(0.021)$ & & \\
\hline $\log \left(\sigma_{t-1}^{m k t}\right)$ & & $\begin{array}{r}0.001 \\
(0.818)\end{array}$ & $\begin{array}{r}-0.005^{* * *} \\
(0.006)\end{array}$ \\
\hline \multirow[t]{2}{*}{$\beta_{i, t-1}^{m k t}$} & & -0.001 & $-0.002^{* * *}$ \\
\hline & & $(0.116)$ & (0.000) \\
\hline \multirow[t]{2}{*}{$\log \left(\sigma_{t-1}^{i n d}\right)$} & & $-0.008^{* * *}$ & 0.001 \\
\hline & & $(0.000)$ & (0.775) \\
\hline \multirow[t]{2}{*}{$\beta_{i, t-1}^{\text {ind }}$} & & $-0.002^{* * *}$ & $-0.003^{* * *}$ \\
\hline & & $(0.003)$ & $(0.000)$ \\
\hline Financial controls & Yes & No & Yes \\
\hline Observations & 83,687 & 91,686 & 83,687 \\
\hline Significance level ( $p$-value) & 0.000 & 0.000 & 0.000 \\
\hline
\end{tabular}

The puzzling positive sensitivity of investment to systematic volatility documented in the baseline OLS model has been eliminated with the implementation of the GMM dynamic panel estimator. These results clearly support the hypothesis that the greater the systematic risk the less the incentive to invest. The application of the GMM dynamic panel estimator removes the major sources of endogeneity inherent in the estimation of the relation between risk and investment and thus enable us to reconcile the mixed results from prior studies. 


\subsection{Sample Splits}

Although both assume a negative investment-risk relation, the traditional view (e.g. market uncertainty under the CAPM) states that it is only the systematic risk that should matter for firm investment; real option theory predicts, on the other hand, that it is total risk that should matter for firm investment. Our results in Table 4 show that both systematic and idiosyncratic risk matter for investment. Therefore, in this section we attempt to examine the predictions of real option models to differences in the irreversibility of capital.

\section{Table 5: GMM dynamic panel estimator of investment on risk by asset specificity}

The table reports the GMM dynamic panel estimator of investment on risk, where the dependent variable is the investment rate $\left(\operatorname{Capx}_{t} / A_{t-1}\right)$. The sample is split into high vs. low asset specificity subsamples. Asset specificity is the ratio of machinery and equipment to total assets. High (low) asset specificity subsamples are comprised of the firms whose asset specificity is above (below) the sample median at the three-digit SIC industry level. Our measure of idiosyncratic risk, $\log \left(\sigma_{i, t-1}^{\text {idio }}\right)$, is constructed from a regression of weekly firm-level returns on the CRSP VW index and the corresponding industry portfolio. Systematic volatility $\left(\log \left(\sigma_{t-1}^{\text {syst }}\right)\right)$ is defined as the (log of the) square root of the difference between the firm's total variance and its idiosyncratic variance. Market volatility $\left(\sigma_{t-1}^{m k t}\right)$ is defined as the square root of the variance of CRSP VW index. $\beta_{i, t-1}^{m k t}$ and $\beta_{i, t-1}^{\text {ind }}$ are coefficient estimates from the regression of weekly firm-level returns on the CRSP VW index and the corresponding industry portfolio. Industry volatility $\left(\sigma_{t-1}^{i n d}\right)$ defined as the square root of the variance of $\mathrm{VW}$ industry portfolio. Financial control variables include lagged values of the investment rate $\left(\operatorname{Lag}\left(\operatorname{Capx}_{t} / A_{t-1}\right)\right)$, lagged values of: Tobin's $Q$ $\log \left(Q_{t-1}\right)$ defined as in Fazzari et al. (1988); operating cash flows $\left(C F_{t-1} / A_{t-2}\right)$ defined as the ratio of operating income to book assets; the firm's size $\left(\log \left(A_{t-1}\right)\right)$ defined as the log value of book assets; the firm's stock return $\left(R_{t-1}\right)$; leverage $\left(E_{t-1} / A_{t-1}\right)$ defined as the ratio of book equity to book assets. The coefficients of these control variables are suppressed for brevity. The sample period is 1970 to 2005. F denotes firm fixed effects, $T$ denotes time fixed effects. The standard errors are clustered at the firm-level, and $p$-values are reported in parentheses. ${ }^{* *},{ }^{* *}$, and ${ }^{*}$ indicate significance at the $1 \%, 5 \%$ and $10 \%$ levels, respectively.

\begin{tabular}{|c|c|c|c|c|}
\hline \multirow[b]{2}{*}{$\operatorname{Capx}_{t} / A_{t-1}$} & \multicolumn{2}{|c|}{ High asset specificity } & \multicolumn{2}{|c|}{ Low asset specificity } \\
\hline & 1 & 2 & 3 & 4 \\
\hline \multirow[t]{2}{*}{$\log \left(\sigma_{i, t-1}^{i d i o}\right)$} & $-0.0024^{*}$ & $-0.0026^{* *}$ & -0.0010 & -0.0016 \\
\hline & $(0.056)$ & $(0.026)$ & $(0.545)$ & (0.300) \\
\hline \multirow[t]{2}{*}{$\log \left(\sigma_{t-1}^{s y s t}\right)$} & $-0.0003^{* *}$ & & -0.0009 & \\
\hline & $(0.047)$ & & $(0.260)$ & \\
\hline \multirow[t]{2}{*}{$\beta_{i, t-1}^{m k t} \sigma_{t-1}^{m k t}$} & & $-0.0005^{* *}$ & & 0.0005 \\
\hline & & $(0.019)$ & & (0.247) \\
\hline \multirow{2}{*}{$\beta_{i, t-1}^{i n d} \sigma_{t-1}^{i n d}$} & & $-0.0006^{* *}$ & & 0.0001 \\
\hline & & $(0.011)$ & & (0.774) \\
\hline Financial controls & Yes & Yes & Yes & Yes \\
\hline Observations & 13,684 & 13,684 & 14,240 & 14,240 \\
\hline Significance level ( $p$-value) & 0.000 & 0.000 & 0.000 & 0.000 \\
\hline
\end{tabular}

The ability to delay investment is valuable when the investment is irreversible, and the future is uncertain. The irreversibility of investment expenditures stems from capital specificity at the industry and/or at the firm level. Dixit and Pindyck (1994) argue that the irreversibility of capital is more pronounced at the industry level because capital is industry-specific.

We split the sample according to the firm's degree of irreversibility and re-estimate the relation between investment and risk using a GMM dynamic panel estimator in two subsamples. We measure a firm's degree of irreversibility using the asset specificity. As in Klasa et al. (2018) and Valta (2012), we compute asset specificity as the ratio of machinery and equipment to book assets. Then the sample is split into high vs. low asset specificity subsamples, where high (low) asset specificity 
subsamples are the firms whose asset specificity is above (below) the sample median at the threedigit SIC industry level.

The results are presented in Table 5. The coefficients on both market and industry risk are significantly negative for irreversible (high asset specificity) firms while the coefficients are insignificant for reversible (low asset specificity) firms. These findings are consistent with real option behaviour when capital is industry-specific. The results on firm-specific risk show a similar pattern: the coefficients are significantly negative for the irreversible subsample but insignificant for the reversible sample. Overall, the main finding is that the greater the degree of asset-specificity of capital (and hence the more irreversible the firm's investments are), the more valuable is the option to delay investment when uncertainty is high.

\section{Conclusion}

Despite a vast theoretical literature that predicts an increase in risk should depress investment, the existing empirical results have been mixed. We recognize that three potential sources of inconsistency may arise when estimating the relation: unobserved heterogeneity, simultaneity and dynamic endogeneity. In an attempt to address these concerns, we use a GMM dynamic panel estimator. Results show that the puzzling positive sensitivity of investment to systematic risk documented in the OLS model has been replaced with a negative relation between investment and systematic risk which supports the hypothesis that the greater the systematic risk the less the incentive to invest. We also provide empirical support for the prediction of real options models with irreversible investment.

\section{References}

Abel, A.B., Eberly, J.C., 1996, Optimal investment with costly reversibility, Review of Economic Studies $63,581-593$.

Arellano, M., Bover, O., 1995, Another look at the instrumental variable estimation of errorcomponents models, Journal of Econometrics 68, 29-51.

Beck, T., Levine, R., Loayza, N., 2000, Finance and the sources of growth, Journal of Financial Economics 58, 261-300.

Bernanke, B.S., 1983, Irreversibility, uncertainty, and cyclical investment, Quarterly Journal of Economics 98, 85-106.

Bloom, N., 2009, The impact of uncertainty shocks, Econometrica 77, 623-685.

Blundell, R., Bond, S., 1998, Initial conditions and moment restrictions in dynamic panel data models, Journal of Econometrics 87, 115-143.

Bulan, L.T., 2005, Real options, irreversible investment and firm uncertainty: new evidence from US firms, Review of Financial Economics 14, 255-279.

Caselli, F., Esquivel, G., Lefort, F., 1996, Reopening the convergence debate: a new look at crosscountry growth empirics, Journal of Economic Growth 1, 363-389.

Dixit, A.K., Pindyck, R.S., 1994. Investment under uncertainty. Princeton university press.

Erickson, T., Whited, T.M., 2000, Measurement error and the relationship between investment and q, Journal of Political Economy 108, 1027-1057. 
Fama, E.F., French, K.R., 1997, Industry costs of equity, Journal of Financial Economics 43, 153-193.

Fazzari, S.M., Hubbard, R.G., Petersen, B.C., Blinder, A.S., Poterba, J.M., 1988, Financing constraints and corporate investment, Brookings Papers on Economic Activity 1988, 141-206.

Froot, K.A., Scharfstein, D.S., Stein, J.C., 1993, Risk management: Coordinating corporate investment and financing policies, Journal of Finance 48, 1629-1658.

Gulen, H., Ion, M., 2016, Policy uncertainty and corporate investment, Review of Financial Studies 29, 523-564.

Holtz-Eakin, D., Newey, W., Rosen, H.S., 1988, Estimating vector auto-regressions with panel data, Econometrica, 1371-1395.

Julio, B., Yook, Y., 2012, Political uncertainty and corporate investment cycles, Journal of Finance 67, 45-83.

Klasa, S., Ortiz-Molina, H., Serfling, M., Srinivasan, S., 2018, Protection of trade secrets and capital structure decisions, Journal of Financial Economics 128, 266-286.

Leahy, J., Whited, T.M., 1996, The effects of uncertainty on investment: Some stylized facts, Journal of Money, Credit, and Banking 28, 64-83.

Nickell, S., 1981, Biases in dynamic models with fixed effects, Econometrica, 1417-1426.

Panousi, V., Papanikolaou, D., 2012, Investment, idiosyncratic risk, and ownership, Journal of Finance 67, $1113-1148$.

Salinger, M., Summers, L.H., 1983, Tax reform and corporate investment: a microeconometric simulation study, In: Behavioral Simulation Methods in Tax Policy Analysis. University of Chicago Press, 247-288.

Valta, P., 2012, Competition and the cost of debt, Journal of Financial Economics 105, 661-682.

Wintoki, M.B., Linck, J.S., Netter, J.M., 2012 Endogeneity and the dynamics of internal corporate governance, Journal of Financial Economics 105, 581-606.

Wooldridge, J.M., 2010. Econometric analysis of cross section and panel data. MIT Press, Cambridge, Massachusetts. 